\title{
2006s-10 \\ The Curse of Windfall Gains in a Non Renewable Resource Oligopoly
}

\author{
Hassan Benchekroun, Ngo Van Long
}

Série Scientifique
Scientific Series

Montréal
Mai 2006

(C) 2006 Hassan Benchekroun, Ngo Van Long. Tous droits réservés. All rights reserved. Reproduction partielle permise avec citation du document source, incluant la notice $\mathbb{C}$.

Short sections may be quoted without explicit permission, if full credit, including $(\mathbb{C}$ notice, is given to the source.
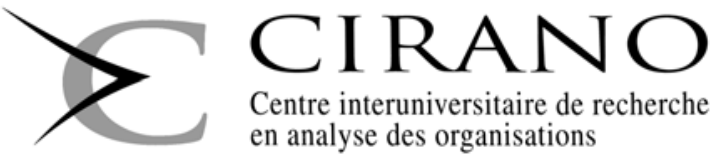

Centre interuniversitaire de recherche en analyse des organisations 


\section{CIRANO}

Le CIRANO est un organisme sans but lucratif constitué en vertu de la Loi des compagnies du Québec. Le financement de son infrastructure et de ses activités de recherche provient des cotisations de ses organisations-membres, d'une subvention d'infrastructure du Ministère du Développement économique et régional et de la Recherche, de même que des subventions et mandats obtenus par ses équipes de recherche.

CIRANO is a private non-profit organization incorporated under the Québec Companies Act. Its infrastructure and research activities are funded through fees paid by member organizations, an infrastructure grant from the Ministère du Développement économique et régional et de la Recherche, and grants and research mandates obtained by its research teams.

\section{Les partenaires / The Partners}

\section{Partenaire majeur}

Ministère du Développement économique, de l'Innovation et de l'Exportation

\section{Entreprises partenaires}

Alcan inc.

Banque du Canada

Banque Laurentienne du Canada

Banque Nationale du Canada

Banque Royale du Canada

Bell Canada

BMO Groupe financier

Bombardier

Bourse de Montréal

Caisse de dépôt et placement du Québec

Fédération des caisses Desjardins du Québec

Gaz Métro

Hydro-Québec

Pratt \& Whitney Canada

Raymond Chabot Grant Thornton

\section{Autres partenaires gouvernementaux}

Industrie Canada

Ministère des Finances du Québec

Ville de Montréal

\section{Partenaires universitaires}

École Polytechnique de Montréal

HEC Montréal

McGill University

Université Concordia

Université de Montréal

Université de Sherbrooke

Université du Québec

Université du Québec à Montréal

Université Laval

Le CIRANO collabore avec de nombreux centres et chaires de recherche universitaires dont on peut consulter la liste sur son site web.

Les cahiers de la série scientifique (CS) visent à rendre accessibles des résultats de recherche effectuée au CIRANO afin de susciter échanges et commentaires. Ces cahiers sont écrits dans le style des publications scientifiques. Les idées et les opinions émises sont sous l'unique responsabilité des auteurs et ne représentent pas nécessairement les positions du CIRANO ou de ses partenaires.

This paper presents research carried out at CIRANO and aims at encouraging discussion and comment. The observations and viewpoints expressed are the sole responsibility of the authors. They do not necessarily represent positions of CIRANO or its partners. 


\title{
The Curse of Windfall Gains in a Non Renewable Resource Oligopoly
}

\author{
Hassan Benchekroun ${ }^{*}$, Ngo Van Long ${ }^{\dagger}$
}

\begin{abstract}
Résumé / Abstract
On étudie les effets de la découverte des stocks de ressources sur les profits des firmes asymétriques. On montre que l'augmentation uniforme des stocks pour toutes les firmes pourrait désavantager celles qui sont initialement les plus grandes. On déduit que la découverte d'une nouvelle technologie qui permet une augmentation d'efficacité d'extraction pour toutes les firmes pourrait réduire le profit de certaines firmes.
\end{abstract}

Mots clés : découverte des stocks, oligopole, ressources naturelles

We investigate the effect of stock discovery on the profits of non-identical oligopolists. We show that a uniform addition to all stocks could harm firms that are originally larger than average. One conclusion that could be drawn from the results is that a new technology that leads to more efficient exploitation of the available resource is not necessarily welcomed by all firms.

Keywords: non-renewable resource, oligopoly, stock discovery

Codes JEL : D43, L13, Q33

\footnotetext{
* Department of Economics and CIREQ, McGill University, 855 Sherbrooke St West, Montreal, H3A 2T7, Canada. Email: hassan.benchekroun@mcgill.ca

${ }^{\dagger}$ CIRANO and CIREQ, Department of Economics, McGill University, 855 Sherbrooke St West, Montreal, H3A 2T7, Canada. Email: ngo.long@mcgill.ca
} 


\section{Introduction}

Resource-extracting oligopolists continually engage in the search for additional stocks or in finding new technologies to transform resources that are economically non-exploitable into resources that can be profitably extracted. If the demand curve facing the industry is elastic, the discovery of additional stocks will raise the industry's profit. It is not clear, however, if all firms will benefit from a windfall "gain" (discovery) that increases the stock of each firm.

In this note, we consider oligopolistic equilibria in subgame-perfect strategies in continuous time ${ }^{1}$, and investigate the effect of stock discovery on the profits of non-identical oligopolists. We show that a uniform addition to all stocks could harm firms that are originally larger than average.

In a static model, this result is not surprising. Starting from a Cournot equilibrium it is well known that a marginal reduction of all firms production will be beneficial to the firms and will move them closer to the cooperative equilibrium. Conversely, increasing the output of all firms is likely to move them further from the cooperative outcome and will reduce their profits. In a dynamic framework with free time horizon, this reasoning is not necessarily valid. The typical extraction path under non-cooperation is monotonically decreasing over time with production level below the production level of cooperative exploitation for at least some interval of time, which we refer to as a scarcity phase ${ }^{2}$. When a firm receives an additional stock it splits its extra-exploitation between the scarcity phase and the phase where production is above the cooperative level. Increasing exploita-

\footnotetext{
${ }^{1}$ Existing models of natural resource oligopoly that use the concept of Markov perfect Nash equilibria are typically based on the assumption that there is only one stock, to which all firms have equal common access. See, for instance, Benchekroun (2003), Benchekroun and Long (2002), Dockner and Sorger (1996), Benhabib and Radner (1992). Our model has $N$ stocks, and we rule out common access.

${ }^{2}$ See for example Dasgupta and Heal (1979) chapter 11, where the extraction path of a nonrenewable resource under monopoly is compared to the extraction path under perfect competition.
} 
tion during the latter phase decreases instantaneous profits whereas increasing exploitation during scarcity phase increases instantaneous profits. The overall impact of increasing stocks on the discounted sum of profits of each firm is therefore unclear. This is what this note seeks to clarify.

\section{The Model}

\subsection{Assumptions and notations}

We consider an oligopoly exploiting a non-renewable resource. There are $N$ firms. Firm $i$ owns a stock of resource $X_{i}(t)$ with $X_{i}(0)=X_{i}^{0}$. Let $X(t)$ denote the sum of all stocks of resource available at time $t$, i.e. $X(t)=\sum_{i=1}^{N} X_{i}(t)$, and let $\vec{X}(t)=\left(X_{1}(t), \ldots, X_{N}(t)\right)$ denote the vector of resource stocks available at time $t$. Define $X_{-i}(t) \equiv X(t)-X_{i}(t)$.

Without loss of generality firms are ranked in an increasing order of their stocks, with firm 1 being the smallest firm: $X_{1}^{0} \leq . . \leq X_{i}^{0} . . \leq$ $X_{N}^{0}$. The rate of extraction of firm $i$ at time $t$ is denoted by $q_{i}(t)$. In the absence of new discoveries, the rate of change of firm $i$ 's resource stock is:

$$
\dot{X}_{i}(t)=-q_{i}(t)
$$

The demand for the extracted resource is assumed stationary and given by

$$
P(Q(t))=(Q(t))^{-\alpha}
$$

where $0<\alpha \leq 1$ and $Q(t)=\sum_{i=1}^{N} q_{i}(t)$. The industry's elasticity of demand is $1 / \alpha \geq 1$.

Let $Q_{-i} \equiv Q-q_{i}$, firm $i$ 's revenue is

$$
R_{i}\left(q_{i}, Q_{-i}\right)=q_{i}\left(q_{i}+Q_{-i}\right)^{-\alpha}
$$


Assume the cost of extraction is zero. The objective function of firm $i$ is to maximize the present value of the stream of cash flow:

$$
\int_{0}^{\infty} q_{i}\left(q_{i}+Q_{-i}\right)^{-\alpha} e^{-r t} d t
$$

subject to

$$
\dot{X}_{i}(t)=-q_{i}(t) \text { with } X_{i}(0)=X_{i}^{0}
$$

\subsection{A Subgame Perfect Nash Equilibrium}

Let $\phi_{i}$ denote an extraction strategy that specifies firm $i$ 's extraction rate at time $t$ as a function of $t$ and of the vector of resource stocks available at time $t$ :

$$
q_{i}(t)=\phi_{i}(t, \vec{X}(t)) .
$$

Each firm $i$ takes its competitor' strategies as given and determines its optimal strategy $\phi_{i}$ that maximizes (1).

Proposition 1: There exists a Markov perfect Nash equilibrium, where the equilibrium strategy of firm $i$ has the property that its extraction rate depends only on its own stock:

$$
q_{i}=(r / \alpha) X_{i}, \text { where } i=1, . ., N .
$$

The discounted sum of profits of firm $i$ when the vector of resource stock is $\vec{X}$ is then

$$
V_{i}(\vec{X})=\left(\frac{\alpha}{r}\right)^{\alpha} X_{i}\left(\sum_{k=1}^{N} X_{k}\right)^{-\alpha}
$$

Proof: See Appendix.

It is interesting to note that, from (2), $\frac{\partial V_{i}}{\partial X_{i}}>0$ : firm $i$ 's valuation

of a marginal additional unit of resource stock $\frac{\partial V_{i}}{\partial X_{i}}$ is higher the smaller its share of resource stock $\left(\frac{X_{i}}{X}\right)$. Moreover, from (2), the larger firm $i$ 's share of the resource stock $\left(\frac{X_{i}}{X}\right)$, the more harmful is an additional unit of resource in the competitors' total available stock (the higher the absolute value of $\left.\frac{\partial V_{i}}{\partial X_{j}}\right)$. 


\subsection{A marginal change in the resource endowment}

The value function for firm $i, V_{i}$, is given by (2). Total differentiation of the value function of firm $i$ gives

$$
d V_{i}=\frac{\partial V_{i}}{\partial X_{i}} d X_{i}+\sum_{j \neq i, j=1}^{N} \frac{\partial V_{i}}{\partial X_{j}} d X_{j}
$$

Using (9) and (10) in the appendix gives

$d V_{i}=\left(\left(\frac{\alpha}{r}\right)^{\alpha}(X)^{-\alpha}\left[1-\frac{\alpha X_{i}}{X}\right]\right) d X_{i}+\sum_{j \neq i, j=1}^{N}\left(-\alpha X_{i}\left(\frac{\alpha}{r}\right)^{\alpha}(X)^{-\alpha-1}\right) d X_{j}$

which after simplification yields

$$
d V_{i}=\left(\frac{\alpha}{r}\right)^{\alpha}(X)^{-\alpha}\left(\sum_{j=1}^{N} d X_{j}\right)\left(\frac{d X_{i}}{\sum_{j=1}^{N} d X_{j}}-\alpha \frac{X_{i}}{X}\right)
$$

We now consider the impact of a potential windfall of resources in the industry: The total resource stock in the industry increases by $d X>0$ where $d X \equiv\left(\sum_{j=1}^{N} d X_{j}\right)$ and where $d X_{j}$ corresponds to the change in the resource stock owned by firm $j$.

Proposition 2: A change in the initial vector of resource stocks of $d \vec{X}=\left(d X_{1}, . ., d X_{N}\right)$ decreases firm $i$ 's discounted sum of profits iff

$$
\frac{d X_{i}}{d X}<\alpha \frac{X_{i}}{X}
$$

Proof: Follows immediately from (3).

Proposition 2 implies that even when $d X_{i}>0$, firm $i$ can see its discounted sum of profits fall. This surprising outcome emerges even 
in the special case where we have a uniform (absolute) windfall of resources (i.e. $d X_{k}=\delta$ for all $k$ ).

Corollary 1: A uniform absolute increase in all stocks by $\delta>0$ (i.e. $d X_{k}=\delta$ for all $k$ ) will diminish firm $i$ 's discounted sum of profits iff

$$
\frac{X_{i}}{X}>\frac{1}{\alpha N} .
$$

Remark 1: This implies that if the initial resource stocks are such that there exists $M \leq N$ such $\frac{X_{M}}{X}>\frac{1}{\alpha N}$ then a uniform windfall gain of all firms' resource stocks by an identical amount $\delta$ will result in a decrease in the discounted sum of profits of firm $i$ for all $i \geq M$. The firms with the largest stocks could be harmed by this uniform gain in the stocks across firms. Note that the impact on firm $i^{\prime} s$ discounted sum of profits depends only on its relative resource stock, i.e. the impact on firm $i$ does not depend on how the change in the stocks is distributed among its competitors. In particular firm $i$ does not care about whether the changes in stocks occur mainly for competitors with bigger (or smaller) stocks.

Remark 2: In the symmetric case where all the initial stocks are equal we have $\frac{X_{i}}{X}=\frac{1}{N}$ for all $i=1, . ., N$ and therefore any increase in all firms' resource stocks by a constant amount will increase each firm's discounted sum of profits, if $0<\alpha<1$.

Remark 3: Consider a proportional windfall gain of all firm's resource stock, i.e., $d X_{i}=s_{i} d X$ for all $i=1, . ., N$. Then

$$
d V_{i}=\left(\frac{\alpha}{r}\right)^{\alpha}(X)^{-\alpha} s_{i}(1-\alpha)\left(\sum_{j=1}^{N} d X_{j}\right)
$$

An increase in the stocks in this case will always result in an increase in the present value of profit flow of each firm if $0<\alpha<1$.

Remark 4: It can be checked, in the case $0<\alpha<1$, that the total industry's profits will increase if and only if $d X>0$. A decrease 
in the total resource stock available will unambiguously result in a decrease of the industry's profits.

Proposition 2 can be reinterpreted as follows: a global increase of all firms' stocks $(d X>0)$ will result in an increase of firm $i$ 's profits if and only if

$$
\frac{d X_{i}}{X_{i}}>\alpha \frac{d X}{X}
$$

A condition for the increase of all firms' profits: a global increase of all firms' stocks $(d X>0)$ will result in an increase of all firms profits if and only if

$$
\frac{d X_{i}}{X_{i}}>\alpha \frac{d X}{X} \text { for all } i
$$

Corollary 2: In the limit case where $\alpha=1$, (i) no increase in stocks that modifies the relative distribution of the resource stocks can increase all firms' profits, and (ii) any increase in stocks that leaves the relative endowments of the resource unchanged will have no impact on firms' profits.

Proof: For the special case $\alpha=1$ the condition (4) yields $\frac{d X_{i}}{X_{i}}>$ $\frac{d X}{X}>0$ for all $i$ which is impossible. Indeed $\frac{d X_{i}}{X_{i}}>\frac{d X}{X}>0$ for all $i$ implies that

$$
\begin{gathered}
d X_{i}>\frac{d X}{X} X_{i} \\
\sum_{i=1}^{N} d X_{i}>\sum_{i=1}^{N} \frac{d X}{X} X_{i}=\frac{d X}{X} \sum_{i=1}^{N} X_{i}
\end{gathered}
$$

since $\sum_{i=1}^{N} d X_{i}=d X$ and $\sum_{i=1}^{N} X_{i}=X$ this condition would imply that $d X>d X$.

From the condition (4) we can note that the smaller $\alpha$ the larger the set of possible increase in resource endowments that result in an increase of all firms' profits. In the following section, we extend our results to the case of non-marginal changes in firms' stocks. 


\subsection{A non-marginal change in the resource endowment}

Let $Y_{i}$ denote the stock of resource owned by firm $i$ (instead of $\left.X_{i}\right)$. We assume

$$
Y_{i}>X_{i} \text { for all } i=1, . ., N
$$

i.e. we consider a new allocation of the resource where each firm owns more stock than initially.

The value function of firm $i$ with the new resource allocation is

$$
V_{i}(\vec{Y})=\left(\frac{\alpha}{r}\right)^{\alpha} Y_{i}\left(\sum_{k=1}^{N} Y_{k}\right)^{-\alpha}
$$

The change in firm $i$ 's profits due to the resource reallocation is

$$
\Delta V_{i}=\left(\frac{\alpha}{r}\right)^{\alpha} Y_{i}\left(\sum_{k=1}^{N} Y_{k}\right)^{-\alpha}-\left(\frac{\alpha}{r}\right)^{\alpha} X_{i}\left(\sum_{k=1}^{N} X_{k}\right)^{-\alpha}
$$

The resource reallocation raises firm $i$ 's profits iff

$$
\Delta V_{i}=\left(\frac{\alpha}{r}\right)^{\alpha}\left(\sum_{k=1}^{N} Y_{k}\right)^{-\alpha} X_{i}\left(\frac{Y_{i}}{X_{i}}-\left(\frac{\sum_{k=1}^{N} Y_{k}}{\sum_{k=1}^{N} X_{k}}\right)^{\alpha}\right)>0
$$

Let $\tau_{i} \equiv \frac{Y_{i}}{X_{i}}-1$ and $\bar{\tau} \equiv \frac{\sum_{k=1}^{N} Y_{k}}{\sum_{k=1}^{N} X_{k}}-1$ denote respectively the percentage change in the resource endowment for firm $i$ and for the whole industry. The reallocation of resource endowments is unprofitable for firm $i$ iff

$$
\tau_{i}<(1+\bar{\tau})^{\alpha}-1
$$


Again, in the limit case where $\alpha=1$, it is impossible to have

$$
\tau_{i}>(1+\bar{\tau})^{\alpha}-1>0 \text { for all } i=1, . ., N
$$

The condition (5) can be interpreted as follows. Assume there is a stock of the resource $\Delta X$ (i.e. $\bar{\tau}=\frac{\Delta X}{\sum^{N}}$ ) to be distributed amongst $\sum_{k=1} X_{k}$

the $N$ firms (where each firm $i$ initially owns $X_{i}$ ), then each firm $i$ should be allocated at least a stock

$$
Y_{i}=\left((1+\bar{\tau})^{\alpha}-1\right) X_{i}
$$

for the profits of firm $i$ not to fall.

An alternative use of condition (5) is to determine conditions on the initial distribution of the resource $\vec{X}$ that will make a uniform increase in all firms' stocks by $\delta$ increase all firms' profits. We seek a condition on the initial stock of firm $i, X_{i}$, such that:

$$
Y_{i}=X_{i}+\delta>\left((1+\bar{\tau})^{\alpha}-1\right) X_{i}
$$

which gives

$$
\frac{\delta}{(1+\bar{\tau})^{\alpha}}>X_{i} .
$$

Profitability for all firms requires

$$
X_{i}<\frac{(1+\bar{\tau})^{\alpha}}{\delta} \text { for all } i=1, . ., N
$$

where $\bar{\tau}=\frac{N \delta}{X}$.Suppose a constant amount of stock, $\delta$, is to be granted to all firms. For this to increase the profits of all firms we must have $\delta>\operatorname{Max}_{i}\left\{(1+\bar{\tau})^{\alpha} X_{i}\right\}$.

\section{Concluding remarks}

One conclusion that could be drawn from the results above is that a new technology that allows for a more efficient exploitation of the 
available resource is not necessarily welcomed by all firms. In particular, consider a joint venture in an $\mathrm{R} \& \mathrm{D}$ project to obtain a technology improvement that results in an increase of the stock of exploitable resource available to each firm. The results of this paper determine the conditions on the new resource allocation that will prevail, under which such a project will draw the participation of the whole industry. Our results also have some political economy implications. Suppose a government decides to authorize exploitation in a geographically area that was initially "protected" (e.g. Alaska and oil exploitation). The results presented in this paper determine conditions that guarantee that the resource allocation resulting from such a policy is profitable to all firms.

Acknowledgement: We thank SSHRC and FQRSC for financial support, and Gerard Gaudet, Kim Long, Koji Shimomura, and Antoine Soubeyran for discussions.

\section{References}

Benchekroun, Hassan, 2003, "Unilateral Production Restrictions in a Dynamic Duopoly", Journal of Economic Theory. Vol. 111 (2), p. 214-239.

Benchekroun, Hassan, and Ngo Van Long, 2002, "Transboundary Fishery: a Differential Game Model", Economica, 69 : 207-229.

Benhabib, Jesse and Roy Radner, 1992, "The Joint Exploitation of a Productive Asset: A Game-theoretic Approach", Economic Theory $2,155-190$.

Dasgupta, P.S. and G.M. Heal, 1979, Economic Theory and Exhaustible Resources, James Nisbet and Cambridge University Press, Cambridge. 
Dockner, Engelbert, and Gerhard Sorger, 1996, "Existence and Properties of Equilibria for a Dynamic Game on Productive Assets", Journal of Economic Theory 71, 209-27. 


\section{Appendix: Proof of Proposition 1}

We need to check that if $q_{j}=(r / \alpha) X_{j}$ for $j \neq i, j=1, \ldots, N$ then firm $i$ 's best reply will be $q_{i}=(r / \alpha) X_{i}$. To verify this claim, we must find a value function $V_{i}(\vec{X})$ such that the following Hamilton-JacobiBellman equation (HJB eq.) is satisfied by the extraction strategy $q_{i}=(r / \alpha) X_{i}$ :

$r V_{i}(\vec{X})=\max _{q_{i}}\left[q_{i}\left(q_{i}+(r / \alpha) X_{-i}\right)^{-\alpha}+\frac{\partial V_{i}}{\partial X_{i}}\left(-q_{i}\right)+\sum_{j \neq i, j=1}^{N} \frac{\partial V_{i}}{\partial X_{j}}\left(-(r / \alpha) X_{j}\right)\right]$

The first order condition yields

$$
\left(q_{i}+(r / \alpha) X_{-i}\right)^{-\alpha}\left[1-\frac{\alpha q_{i}}{q_{i}+(r / \alpha) X_{-i}}\right]-\frac{\partial V_{i}}{\partial X_{i}}=0
$$

We conjecture that the value function is

$$
V_{i}(\vec{X})=\left(\frac{\alpha}{r}\right)^{\alpha} X_{i}\left(\sum_{k=1}^{N} X_{k}\right)^{-\alpha}
$$

The partial derivatives of this function are

$$
\begin{gathered}
\frac{\partial V_{i}}{\partial X_{i}}=\left(\frac{\alpha}{r}\right)^{\alpha}(X)^{-\alpha}\left[1-\frac{\alpha X_{i}}{X}\right]>0 \\
\frac{\partial V_{i}}{\partial X_{j}}=-\alpha X_{i}\left(\frac{\alpha}{r}\right)^{\alpha}(X)^{-\alpha-1}<0 \text { for } j \neq i .
\end{gathered}
$$

Substituting (9) and (10) into(7) yields the solution

$$
q_{i}=\frac{r X_{i}}{\alpha}
$$

We must check that, after the substitution of (9), (10) and (11) into the right-hand side of the HJB equation, and the value function conjectured in (8) into the left-hand side of the HJB equation (6), we do get an identity. 
Substituting (9), (10) and (11) into the right-hand side of the HJB equation, we get

$$
\mathrm{RHS}=\left(\frac{\alpha}{r}\right)^{\alpha}(X)^{-\alpha}\left(\frac{r X_{i}^{2}}{X}\right)+\sum_{j \neq i, j=1}^{N} \alpha X_{i}\left(\frac{\alpha}{r}\right)^{\alpha}(X)^{-\alpha-1}\left(\frac{r X_{j}}{\alpha}\right)
$$

or

$\operatorname{RHS}=r\left(\frac{\alpha}{r}\right)^{\alpha}(X)^{-\alpha-1}\left(X_{i}^{2}+\sum_{j \neq i, j=1}^{N} X_{i} X_{j}\right)=r\left(\frac{\alpha}{r}\right)^{\alpha} X_{i}\left(\sum_{k=1}^{N} X_{k}\right)^{-\alpha}$

which is identical to the left-hand side, $r V_{i}(\vec{X})$, of the HJB equation. 